\title{
Thoughts on Yunnan Province's Strengthening International Capacity Cooperation with South Asia and Southeast Asia
}

\author{
Li Jianhua $1 *$ \\ School of Urban and Environment, Yunnan University of \\ Finance and Economics,Kunming, Yunnan, China \\ mliye616@sina.com
}

\author{
Cheng Zhenhuang 2 \\ Yunnan Academy of macroeconomics research,Kunming, \\ Yunnan, China \\ czh701301@126.com
}

\begin{abstract}
According to the significant decision made by the State Council in its guidance on Promoting International capacity cooperation and Equipment manufacturing and the state's important task to build Yunnan Province into an economic hub for South Asia and Southeast Asia, Yunnan Province seizes the historical opportunity based on its actual development situation and proposes the overall idea of strengthening International capacity cooperation from eight aspects.
\end{abstract}

Keywords-Opening-up, international capacity cooperation, South Asia and Southeast Asia, "going out"

\section{INTRODUCTION}

Opening-up is China's basic policy. Promoting International capacity cooperation is a win-win initiative for Yunnan Province to be deeply integrated with the global economy and a move to achieve complementary advantages and common development. In March 2018, Premier Li Keqiang proposed that "China will create a new landscape in all-round opening-up. China will further expand the scope and raise the quality of its opening up; and we will use high-standard opening up to generate high-quality development". And he also proposed that "China will further expand International capacity cooperation to drive Chinese manufacturing and Chinese services to go out." in his report on the work of the government.

The "the Belt and Road Initiative" strategy, the construction of China-ASEAN free trade area, the Bangladesh -China- India - Myanmar (BCIM) economic corridor and the strategic mechanism of cooperative development of Lancang-Mekong river are all centered in Yunnan, which is an important opportunity for the further opening-up of Yunnan Province. Faced with the task of building the economic hub in South Asia and Southeast Asia in Yunnan Province, we will guide and serve enterprises to successfully complete international capacity cooperation and establish a new pattern of foreign development with mutual benefit through institutional arrangements and policy implementation.

Strengthening international capacity cooperation in Yunnan is the regional layout and detailed implementation under the national opening-up strategy. Based on the historical development and current situation, Yunnan's industry is less developed in China, while compared with south and southeast Asian countries, Yunnan has comparative advantages in industries such as electricity, mining, steel etc. In recent years, the production capacity cooperation fields between Yunnan enterprises and Laos, Myanmar, Vietnam, Cambodia and other neighboring

countries are mainly implemented at four levels. First, investments are made in infrastructure such as roads, airports and communications. Second, investments are made in agriculture, forestry and animal husbandry. Investments are also made in the fields of energy, steel, non-ferrous metal mining etc. Other cooperation fields include investment in tourism, culture and services and trade.

On August 1st, 2017, China began to carry out the provisions of AAAA, Financial Management Regulations for Overseas Investment of State-owned Enterprises. The contents of this regulation have clarified the financial management requirements of enterprises' overseas investment and the whole process management is emphasized. Meanwhile, the internal control management and performance management of overseas company's operation activities shall be strengthened to improve the company's operation capability. Thus enterprises in Yunnan are required to form specialized and standardized operation in international capacity cooperation.

It is a systematic and long-term process to drive enterprises to "go out" and promote international capacity cooperation. At present, the political situation of south and Southeast Asian countries is relatively stable and the desire to develop economy is urgent. Yunnan's geographic advantages contributes to the mutual understanding and exchange between multi-parties. Laos, Myanmar, Cambodia and other 
countries have backward infrastructure and underdeveloped market economy, which is an important bottleneck affecting our further integration in the future. Therefore, we should improve the security capability of overseas investment and safeguard the legitimate overseas rights and interests of Chinese citizens and legal persons.

\section{GENERAL IDEA}

After years of effort and practice, the work focus on promoting International capacity cooperation in Yunnan will inevitably shift from theory to practice. According to the policies, regulations and laws such as the Implementation Scheme of Building an Economic and Trade Center for Southeast Asia and South Asia in Yunnan Province, the Joint Statement on Production Capacity Cooperation in Countries along Lancang-Mekong River, the Five-year Action Plan of Cooperation in Lancang-Mekong River, the development ideas can be discussed in the following aspects:

A. On the premise of upholding mutual benefit, justice and profit, openness and inclusiveness, Yunnan's advantages of capacity, capital, technology and talents are effectively combined with the development needs of relevant countries.

B. We will perfect the coordination mechanism of international capacity cooperation.

- We will further improve the government coordination mechanism and accelerate the platform construction of bilateral and multilateral cooperation mechanisms.

- We will construct a cooperative mechanism linked with governments, sub-regional cooperation organizations, enterprises, trade associations, intermediary service agencies.

- We give full play to the bond of overseas Chinese, Chinese chamber of commerce and social organizations.

C. We will make cooperative planning and recent development plans between Yunnan southeast Asian countries in South Asia and enhance the government's service capacity for overseas enterprises.

- The information communication channels between the two sides will remain open.

- We will perfect the project database of information communication channel and investment promotion mechanism.

- We will accelerate the compilation of Action Plan on Participation in " the Belt and Road Initiative" Foreign Investment Cooperation for Yunnan Province and other specific implementation plans for International capacity cooperation.

D. We will accelerate the cultivation of market participants with international competitiveness and market development ability.
- We will promote the "going-out" state-owned enterprises to be bigger, stronger and better.

- We will organize enterprises in Yunnan Province to actively participate in key fields of bilateral cooperation.

- We will cultivate entrepreneurs. system.

E. We will establish an all-round finance-supporting

- We will promote the reform of Yunnan's international financial system.

- We will make active preparations for the establishment of international capacity cooperation fund.

- We will strengthen cooperation with Asian Development Bank, Asian Infrastructure Investment bank, Asian Financial Cooperation Association and World Bank and other institutions.

- The summary takes the form of the experience and lessons of EP (design- procurement), EPC(design-procurement-construction),BOT(constr uction-operation-handover), $\mathrm{BOO}$ (construction-own ership-operation), PPP (public-private partnership), mergers and acquisitions and financial leasing etc.

F. We will focus on effectiveness of risk prevention mechanism of international capacity cooperation.

- We will strengthen the early warning and warning of major risks in overseas investment cooperation and the construction of the safeguard mechanism to deal with the emergency plan.

- We will prudently take into consideration the risk factors of the development level of market economy in related countries and the continuity and consistency of economic cooperation laws and regulations.

- We will support financial institutions to innovate solutions for financial products and services for enterprises to "go out".

G. We will consolidate the achievements of the previous cooperation.

- We will continue to develop the key pilot areas, economic cooperation zones along the borders, cross-border economic cooperation zones, airport economic zones and comprehensive bonded zones.

- We will make good use of new opportunities to explore the establishment of Lancang-Mekong National Capacity and Investment Cooperation Promotion Alliance and Lancang-Mekong Business Council.

H. We will construct the education and training system of international talents such as law, auditing, etc.

- We will utilize the strength of colleges and universities, scientific research institutions, 
vocational colleges and technical schools in our province.

- It is planned to set up a think tank for foreign cooperation in Yunnan province.

In view of the above ideas, Yunnan should integrate advantages; further accelerate the pace of opening up to South Asia, Southeast Asia and more countries. We should supervise and guide enterprises to abide by the laws of market economy, keep promises, and build community of shared interests and responsibility. Meanwhile, we should endeavor to prevent risks. We also face up to differences in social development levels such as legal environment, cultural and religious characteristics of both sides. We will pursue deep cooperation between the two sides and ensure the volume and quality of international capacity cooperation through strategic cooperation, green cooperation, intellectual property cooperation and talent cooperation.

\section{REFERENCES}

[1] Xu Shaoshi. the Belt and Road Initiative and the Survival Skills of Cooperative Enterprises in International Capacity Cooperation [M]. China Machine Press, 2017:4. (In Chinese)
[2] Xu Shaoshi. the Belt and Road Initiative and the Ice-breaking of the Local Development in International Capacity Cooperation [M]. China Machine Press, 2017:4. (In Chinese)

[3] Wu Jiansheng. On Thoughts, Emphases and Countermeasures of International Capacity Cooperation. [M]. Economic Science Press, April 2017.(In Chinese)

[4] Ren Wen. Policy-based Credit Insurance Promotes Cooperation in National Production Capacity and Equipment Manufacturing. [J]. International Engineering and Labor Services, 2017:(7) (In Chinese)

[5] Guo Jianluan Yan Dong. Risk and Strategy of International Capacity Cooperation under the Belt and Road Initiative [J]. International Trade, April 2017.(In Chinese)

[6] Qiao Xiaonan Zhang Xiaoning. International Capacity Cooperation and the Economic Logic of Finance Support and Win-win [J]. Industrial Economy, March 2017. (In Chinese)

[7] Zhao Jing. Strategic Research on International Capacity Cooperation between China and ASEAN [J] Macroeconomic Management, May 2017. (In Chinese) 